\title{
DR-55. SYNTHESIS, SPECTROSCOPIC CHARACTERIZATION AND MOLECULAR DOCKING STUDIES OF 2-BUTYL-4-CHLORO-5-FORMYLIMIDAZOLE THIOSEMICARBAZONE COBALT (II) COMPLEX
}

\author{
A. Sreenath Reddy ${ }^{1}$, L. Sivarama Krishna ${ }^{2}$, Vishnu Nayak Badavath ${ }^{3}$, G. Sravya ${ }^{4}$, \\ N. Bakthavatchala Reddy ${ }^{4}$, G. V. Zyryanov ${ }^{4,5}$ \\ ${ }^{1}$ State Key Laboratory of Oil and Gas Reservoir Geology and Exploitation, \\ Southwest Petroleum University, Chengdu, Xindu, 610500, PR China \\ ${ }^{2}$ Chemical Technology, Faculty of Sciences, Chulalongkorn University, \\ Bangkok, 10330, Thailand \\ ${ }^{3}$ Department of Microbiology, Faculty of Medicine, Chulalongkorn University, \\ Bangkok, 10330, Thailand \\ ${ }^{4}$ Ural Federal University of the first President of Russia B. N. Yeltsin, \\ Mira St., 19, Yekaterinburg, 620002, Russia \\ ${ }^{5}$ I. Ya. Postovsky Institute of Organic Synthesis UB RAS, \\ S. Kovalevskoy/Akademicheskaya St., 20/22, Yekaterinburg, 620990, Russia \\ E-mail: drreddyaabaka@yahoo.com
}

A novel 2-Butyl-4-chloro-5-formylimidazole thiosemicarbazone cobalt (II) complex is synthesized and characterized by using spectroscopic techniques like elemental analysis, FT-IR, HRMS, electronic spectral analysis and Powder-X-ray diffraction. The Co (II) complex is found to be highly efficient in inhibiting the growth of human pathogens like $S$. aureus, B. megaterium with MIC value $12,0 \mu \mathrm{g} / \mathrm{mL}$ whose inhibition zones are almost comparable with the standard antibiotic. The synthesized complex well occupy in the active site of $\beta$-ketoacyl-acyl carrier protein synthase III enzyme (PDB: 1MZS), in consists of catalytic triad and adenine-binding site, so the designed compounds are promising for to treat bacterial infection. 